\title{
The Relationship of Digit Ratio (2D:4D) With Cerebral Lateralization and Grip Strength in Elite Swimmers
}

\author{
Hakan Acar ${ }^{1}$, Nebahat Eler ${ }^{1}$ \\ ${ }^{1}$ Department of Physical Education and Sport, Bulent Ecevit University, Zonguldak, Turkey \\ Correspondence: Hakan Acar, Department of Physical Education and Sport, Bulent Ecevit University, Zonguldak, \\ Turkey.
}

Received: February 25, 2018

Accepted: March 4, 2018 Online Published: March 11, 2018

doi:10.11114/jets.v6i4.3040

URL: https://doi.org/10.11114/jets.v6i4.3040

\begin{abstract}
The index finger and the 4th finger ratio (2D:4D) is the indicator of the prenatal testosterone. The aim of this study is to investigate the relationship between $2 \mathrm{D}: 4 \mathrm{D}$, hand preference and hand grip strength in swimmers. A total of 80 elite swimmers, participated in the study. Height, body weight, body mass index (BMI), hand 2D:4D finger measurements and hand grip strength tests were performed for athletes. The hand preference was determined by the Oldfield questionnaire and it was evaluated according to the Geschwind score. The data were recorded in the SPSS 20 program and $p<0.05$ was considered as statistically significant. It was found that in both men and women, a negative correlation was found between right and left hand 2D:4D and both dominant (DHGS) and non-dominant hand grip strength (NDHGS) values. It was found that men had lower 2D:4D ratio than women. For both right and left handed, there was a statistically significant difference between the right and left hand 2D:4D ratios in both men and women ( $<<0.05)$ and the dominant hand (DH) 2D:4D ratios were found to be lower than non-dominant hand (NDH) 2D:4D ratios in both men and women $(\mathrm{p}<0.05) \quad$ It can be said that the 2D:4D ratios may be the effect of determining the hand preference, the grip strength and therefore the strength.
\end{abstract}

Keywords: elite swimmer, 2d:4d, lateralisation, handgrip strength

\section{Introduction}

The force is one of the basic biometric skills and it has a worthless value for every sport branch (Acar 2000). In order to generate and develop strength, the diameter of the muscle fibres must be increased, and fort he increase of the muscle fibers, there must be sufficient testosterone hormone in it (Muratl1 2007).

The different concentrations of testosterone and oestrogen hormones in the uterus determine the proportion of the finger lengths of the child (Manning et al. 1998). 2D:4D finger length ratios were adopted as an indicator of to what level people were exposed to testosterone in their mother's womb (Powell 2012).Second and fourth digit ratio (2D:4D) is the ratio of the length of the second digit to that of the fourth digit. The fourth digit is the ring finger of the human hand and the second most ulnar finger located between the middle finger and the little finger. The second digit is the index finger, which is the first finger and the second digit of the human hand (Oladipo et al. 2017). Manning et al. (1998) have suggested that the ratio between the lengths of the 2nd (index) and 4th (ring) fingers (the 2D:4D ratio), a sexually dimorphic trait with lower mean 2D:4D in males compared to females, is negatively related to prenatal testosterone and positively related to estrogen (Manning et al. 1998). This relationship is negatively associated with sportive performance (Hönekopp \& Shuster, 2010).

The negative correlation between 2D:4D and physical power is assumed to affect sports performance (Hönekopp et al., 2006; Malas et al., 2006). In many studies, 2D:4D finger ratio showed a negative correlation with physical fitness (Manning, 2002; Manning and Taylor, 2001). Low 2D:4D ratio is considered to be associated with high performance levels in many sports branches (Manning and Taylor, 2001; Manning, 2002; Paul et al. 2006; Bennett et al. 2010; Longman et al. 2011). Sports performance depends on both an advanced cardiovascular system and muscle strength. There is a more direct relationship between 2D:4D and muscle strength (Tamiya et al. 2012).

There are studies which shows the relationship between 2D:4D, muscle strength and hand grip strength (Fink et al., 2006; Moffit and Swanik, 2010). Hand grip strength is the factor that determines total muscle strength in children, adolescents and young adults and it is an indicator of overall health and physical strength (Groslambert, 2002; 
Massey-Westrop et al. 2004; Foo, 2007; Wind et al. 2010; Tamiya et al. 2012). At the same time, the grip strength is one of the basic functions of the upper extremity (Kaplan, 2016). Anthropometric properties in swimming, especially effects the strength of the upper extremity. Elite swimmers have longer arms and a wider surface hand area (Troup, 1999). For this reason, in swimmers it is important to examine the grip strength, which is considered to be an indicator of physical strength, along with anthropometric measurements and 2D:4D ratio.

The fact that 2D:4D ratio is negatively associated with physical strength and sportive performance (Hönekopp \& Schuster, 2010), it can be explained as a biological marker for performance in various sports (Manning et al. 1998; Hönekopp \& Schuster, 2010). The ratio of finger lengths to each other was determined in the mother's womb and did not change in the adolescent period or in the adult period (Çelik et al. 2010). If it is consider the importance of determining the talent identification at young ages to achieve the highest level of performance in sport, it will be better understood the importance of the relationship of strength with 2D:4D ratio, which is associated with high performance level. In this field there are studies in the literature for various branches (Manning \& Taylor, 2001; Manning, 2002; Pokrywka et al. 2005; Hönekopp et al. 2006; Voracek et al. 2006; Tester \& Campell 2007; Bennett et al. 2010), however, studies which is conducted for swimmers is limited in the literature (Jurimae et al. 2008; Sudhakar et al. 2013). Our study is also the first study to investigate the relationship between 2D:4D with hand preference and strength together in this field. The aim of this study was to investigate the relationship between $2 \mathrm{D}: 4 \mathrm{D}$, hand preference and hand grip strength in elite swimmers.

\section{Method}

A total of 80 Elite swimmers, 41 male and 39 female, participated in the study. The height, body weight, BMI and hand preferences of these athletes were determined and 2D:4D finger measurements and hand grip strength tests were performed.

Holtain brand anthropometric set was used for measurements. Weight measurement of athletes, precision degree $0,1 \mathrm{~kg}$ sensitive digital pressure, length measurement, $0.01 \mathrm{~m}$ and BMI was calculated by the ratio of the body weight $(\mathrm{kg}) /$ length $\left(\mathrm{m}^{2}\right)$ formula in the sensitivity scale.

In the determination of preferences for lateralization, hand selection was determined by the Oldfield questionnaire and evaluated according to the Geschwind score .Grouping was made as full-handed right-handed ones and "right handed, left-handed ones, and full "left-handed" After the two hands of the athletes have been photocopied, the second hand is on the palmar side. 2th finger (index finger) and 4th finger (ring finger) lengths were determined using calliper, which can measure up to $0.05 \mathrm{~mm}$, between the basal line and pulpa in proximal section. Measurements were made twice by the same person to ensure reliability, measured in millimetres $(\mathrm{mm})$. In order to determine the ratio, the second finger length is divided into the fourth finger length. Hand grip strength values were measured by using the hand dynamometer in accordance with international standards. The measurements with Jamar hydraulic dynamometer (Sammons Preston, USA) were first started from the dominant side. Measurements were made in the athletes at seated position without getting support from the body while the front arm was at $90^{\circ}$ flexion position. The right and left hand were measured twice separately and the best value was recorded as $\mathrm{kg}$.

The data were evaluated in SPSS 16. T-test and correlation analysis were used in statistical analysis.

\section{Results}

Table 1. Some demographic features of the athletes

\begin{tabular}{|c|c|c|c|c|c|c|c|c|c|c|c|c|c|c|c|c|}
\hline \multirow{2}{*}{$\begin{array}{l}\text { Gender } \\
\text { Hand } \\
\text { preference }\end{array}$} & \multicolumn{8}{|c|}{ Male } & \multicolumn{8}{|c|}{ Female } \\
\hline & \multicolumn{5}{|c|}{ Right-handed } & \multicolumn{3}{|c|}{ Left-handed } & \multicolumn{5}{|c|}{ Right-handed } & \multicolumn{3}{|c|}{ Left-handed } \\
\hline & Ave. & SD & Min & Max & Ave. & SD & Min & Max & Ave. & SD & Min & Max & Ave. & SD & Min & Max \\
\hline Age & 20,76 & 2,63 & 17,00 & 27,00 & 20,50 & 3,51 & 14,00 & 26,00 & 20,33 & 2,12 & 17,00 & 26,00 & 20,11 & 2,62 & 17,00 & 24,00 \\
\hline Sport age & 14,03 & 2,70 & 10,00 & 21,00 & 13,38 & 3,46 & 8,00 & 18,00 & 13,30 & 2,47 & 8,00 & 19,00 & 13,56 & 2,51 & 10,00 & 17,00 \\
\hline Height $(\mathrm{cm})$ & 185,24 & 5,52 & 175,00 & 205,00 & 181,50 & 3,85 & 176,00 & 186,00 & 175,03 & 5,04 & 167,00 & 185,00 & 174,11 & 3,98 & 168,00 & 180,00 \\
\hline Weight $(\mathbf{k g})$ & 82,18 & 5,78 & 72,00 & 102,00 & 79,75 & 4,46 & 75,00 & 86,00 & 65,67 & 6,18 & 55,00 & 80,00 & 65,67 & 4,74 & 59,00 & 74,00 \\
\hline BMI & 23,92 & 0,67 & 21,59 & 25,73 & 24,19 & 0,45 & 23,67 & 24,85 & 21,37 & 0,91 & 19,25 & 23,37 & 21,62 & 0,66 & 20,71 & 22,83 \\
\hline
\end{tabular}

Table 2. Hand distribution preference of the athletes

\begin{tabular}{lccccc}
\hline \multicolumn{5}{c}{ Hand preference } \\
& n & \% & \multicolumn{2}{c}{ Left-handed } & Total \\
& n & \% & \\
\hline Male & 33 & 80,48 & 8 & 19,52 & 41 \\
Female & 30 & 76,92 & 9 & 23,08 & 39 \\
Total & 63 & 78,75 & 17 & 21,25 & 80 \\
\hline
\end{tabular}

It was found that $80,48 \%$ of men were right handed, $19,52 \%$ were left handed, and $76,92 \%$ of girls were right handed 
and $23.08 \%$ were left handed. There is no significant difference was found between gender and dominant hand $(\mathrm{p}>0,05)$.

Table 3. Hand preference of the athletes, 2D:4D and values of gripping strength values

\begin{tabular}{lcccccccccccccccccc}
\hline & \multicolumn{1}{c}{} & \multicolumn{1}{c}{ Male } & \multicolumn{1}{c}{ Right-handed (n-54) } & \multicolumn{4}{c}{ Left-handed (n-13) } & \multicolumn{4}{c}{ Right-handed (n-56) } & \multicolumn{4}{c}{ Left-handed (n-11) } \\
& Ave. & SD & Min & Max & Ave. & SD & Min & Max & Ave. & SD & Min & Max & Ave. & SD & Min & Max \\
\hline Right hand 2D:4D & 0,93 & 0,02 & 0,89 & 0,97 & 0,96 & 0,01 & 0,94 & 0,97 & 0,95 & 0,02 & 0,92 & 0,99 & 0,99 & 0,01 & 0,96 & 1,00 \\
Left hand 2D:4D & 0,97 & 0,02 & 0,91 & 1,00 & 0,92 & 0,02 & 0,91 & 0,94 & 0,99 & 0,01 & 0,96 & 1,01 & 0,95 & 0,02 & 0,93 & 0,97 \\
DHGS & 47,79 & 6,44 & 35,00 & 59,00 & 46,00 & 5,35 & 40,00 & 54,00 & 35,43 & 3,94 & 27,00 & 42,00 & 35,78 & 4,87 & 30,00 & 46,00 \\
NDHGS & 46,42 & 6,47 & 34,00 & 58,00 & 44,38 & 5,55 & 39,00 & 54,00 & 33,63 & 3,85 & 26,00 & 40,00 & 33,22 & 5,17 & 27,00 & 44,00 \\
\hline
\end{tabular}

In our study, the highest grip strength was found to be NDHGS $47.79 \mathrm{~kg}$ in right handed men and the lowest grip strength was NDHGS $33.22 \mathrm{~kg}$ in left handed women. The average of 2D:4D according to hand preferences in men was found to be lower than in women.

Table 4. Correlation between 2D:4D and hand grip strength according to hand preferences

\begin{tabular}{|c|c|c|c|c|c|c|}
\hline & & & \multicolumn{2}{|c|}{ DHGS } & \multicolumn{2}{|c|}{ NDHGS } \\
\hline & & & $\mathbf{r}$ & p & $\mathbf{r}$ & $\mathbf{p}$ \\
\hline \multirow{4}{*}{ Male } & \multirow{2}{*}{ Right-handed } & Right hand 2D:4D &,$- 538^{* *}$ & .001 &,$- 585^{* *}$ & .000 \\
\hline & & Left hand 2D:4D &,$- 462^{* *}$ & .007 &,$- 463^{* *}$ & .007 \\
\hline & \multirow{2}{*}{ Left-handed } & Right hand 2D:4D &,- 665 & .072 &,- 615 & .104 \\
\hline & & Left hand 2D:4D &,$- 866^{* *}$ & .005 &,$- 787^{*}$ & .020 \\
\hline \multirow{4}{*}{ Female } & \multirow{2}{*}{ Right-handed } & Right hand 2D:4D &,$- 679^{* *}$ & .000 &,$- 697^{* *}$ & .000 \\
\hline & & Left hand 2D:4D &,$- 470^{* *}$ & .009 &,$- 483^{* *}$ & .007 \\
\hline & \multirow{2}{*}{ Left-handed } & Right hand 2D:4D &,- 048 & .901 &,- 057 & .884 \\
\hline & & Left hand 2D:4D &,- 345 & .363 &,- 365 & .334 \\
\hline
\end{tabular}

It is found that there was statistically significant difference between 2D:4D with either DHGS and NDHGS in both male and female right handed players $(\mathrm{p}<0.05)$. Negative correlations were found in all left handed players. But only in left handed men, significant difference was found between left hand 2D:4D and grip strength $(\mathrm{p}<0.05)$. There was no significant difference was found between the other groups ( $p>0.05)$. In left handed girls, the correlation between right hand 2D:4D and DHGS,NDHGS was determined as the lowest negative correlations ( $\mathrm{r}=-, 048, \mathrm{r}=-, 057)$, and in left handed men, the correlation between left hand 2D:4D and DHGS,NDHGS was determined as the highest negative correlations in this study $(\mathrm{R}=-, 866, \mathrm{R}=-787)$.

Table 5. Correlation between 2D:4D and gripping strength of the athletes with regard to some of their features

\begin{tabular}{lcccccccc} 
& \multicolumn{2}{c}{ Right hand 2D:4D } & \multicolumn{2}{c}{ Left hand 2D:4D } & \multicolumn{2}{c}{ DHGS } & \multicolumn{2}{c}{ NDHGS } \\
& $\mathbf{r}$ & $\mathbf{p}$ & $\mathbf{r}$ & $\mathbf{p}$ & $\mathbf{r}$ & $\mathbf{p}$ & $\mathbf{r}$ & $\mathbf{p}$ \\
\hline Age &,- 008 &, 947 &, 001 &, 993 &, 110 &, 332 &, 103 &, 362 \\
Sport age &,- 062 &, 585 &,- 037 &, 745 &, 093 &, 412 &, 088 &, 438 \\
Height &,$- 419^{* *}$ &, $\mathbf{0 0 0}$ &,- 199 &, 077 &, $551^{* *}$ & $\mathbf{, 0 0 0}$ &, $570^{* *}$ &, $\mathbf{0 0 0}$ \\
Weight &,$- 418^{* *}$ & $\mathbf{, 0 0 0}$ &,$- 412^{* *}$ & $\mathbf{, 0 0 0}$ &, $660^{* *}$ & $\mathbf{, 0 0 0}$ &, $667^{* *}$ &, $\mathbf{0 0 0}$ \\
\hline
\end{tabular}

It is determined that there was no statistically significant correlation between age and sports age and left and right hand $2 \mathrm{D}: 4 \mathrm{D}$ ratios $(\mathrm{p}>0.05)$. It was found that there was a significant correlation with the ratio of right hand 2D:4D compared to the ratio of right hand 2D:4D $(\mathrm{p}<0.05)$. There were no significant differences between the two groups $(\mathrm{p}<0.05)$.It was determined that both DHGS and NDHGS had a statistically significant relationship with height and BMI ( $<<0.05$ ), but not with age and sport age. 
Table 6. Comparison of DH and NDH with 2D:4D

\begin{tabular}{lllccccc}
\hline Sex & Hand Preference & & n & Ave. & SS & t & p \\
\hline \multirow{4}{*}{ Male } & Left Handed & DH 2D:4D & 8 & 0,923 & 0,015 & \multirow{2}{*}{9.817} & \multirow{2}{*}{ 0,000 } \\
& & Night handed 2D:4D & 33 & 0,964 & 0,017 & & \\
& & DH 2D:4D & 33 & 0,932 & 0,017 & -12.121 & $\mathbf{0 , 0 0 0}$ \\
& & NDH 2D:4D & 8 & 0,966 & 0,021 & & \\
\multirow{5}{*}{ Female } & \multirow{2}{*}{ Left Handed } & DH 2D:4D & 9 & 0.954 & 0,015 & \multirow{2}{*}{8.194} & $\mathbf{0 . 0 0 0}$ \\
& & NDH 2D:4D & 30 & 0.985 & 0,018 & & \\
& \multirow{2}{*}{ Right Handed } & DH 2D:4D & 30 & 0.952 & 0,016 & -11.212 & $\mathbf{0 , 0 0 0}$ \\
\hline
\end{tabular}

According to the $t$ test results in the independent groups, statistically significant differences were found between male and female left and right handed 2D:4D averages $(\mathrm{p}<0.05)$. Right hand 2D:4D ratios are higher at the left handed and left hand 2D:4D ratios are higher at the right handed ones.

\section{Discussion}

In the present study, $80.48 \%$ of the participants were right handed hand, $19.52 \%$ were left handed, and $76.92 \%$ of the girls were right handed, $23.08 \%$ were left handed. In a study, conducted by Loffing et al. (2012), volleyball players $(\mathrm{n}=36)$ left handedness rate was determined as $11.11 \%$. The right hand oppression in Turkey is seen in $85-90 \%$ of the population (Kütükçüoğlu, 1993). Being left handed in many branches can provide significant advantages for the athlete. This may be associated with athletes' left hand preference rates being higher than the normal population.

In our study, it was determined that, right-handed male athletes; DHGS 47,79 kg, NDHGS 46,42 kg, left-handed male athletes DHGS 46,00 kg, NDHGS 44,38 kg, right handed female athletes; DHGS 35,43 kg, NDHGS 33,63 kg, left-handed female athletes; DHGS 35,78 kg, NDHGS 33,22 kg. In male and female athletes, DHGS values were higher than NDHGS values. Atabek (2014), identified the mean age of female handball players as $32.22 \pm 3.93 \mathrm{~kg}$. Koley et al. (2011), determined that women's handball players right grip strength average was $30.01 \mathrm{~kg}$. and left grip strength was $26.80 \mathrm{~kg}$. Gümüs (2017), determined the averages of elite male fencers DHGS as $44.2 \mathrm{~kg}$ in right handed, $43.9 \mathrm{~kg}$ in left handed, for NDHGS in right handed $42.8 \mathrm{~kg}$, in left handed $41.5 \mathrm{~kg}$. In all studies, the average of the athletes groups was given and the results of the study showed close averages. Although the hand grip strength averages are similar to the grip strength averages in swimmers, the hand grip strength determines total muscle strength, and the overall health and physical strength is considered a physical strength indicator. Despite the fact that the ball in the handball and the fencing in the fencing are constantly grasped by hand,the hand grip strength averages are similar to the grip strength averages in swimming, the grip strength is predictive of total muscle strength and the general health and physical strength are considered as an indication of a physical strength.

There was a statistically significant difference between 2D:4D and DHGS and NDHGS in both male and female right handed hands $(\mathrm{p}<0.05)$. Lu et al., (2017), determined negative significant differences between 2D:4D and hand grip strengths in his study $(\mathrm{n}=346)$. The results are similar and support the literature knowledge (Hönekopp \& Shuster, 2010) that the 2D:4D ratio is negatively associated with force, physical strength and athletic performance. In this study, it was found that men had lower 2D:4D ratio than women. Manning (2002) and Lutchmaya et al. (2004) found that the male athletes 2D:4D ratio in both hands was lower than female athletes in their studies. Lu et al. (2017), found similar results in the study ( $\mathrm{n}=346$ ), and all of these results, which were lower for men's 2D:4D average than women (Manning et al, 1998; Manning and Taylor 2001; Hönekopp \& Watson, 2011; Van Honka et al. 2011) confirm the literature information. In our findings, the 2D:4D averages are lower than the 2D:4D averages in both men and girls. This means that 2D:4D ratios can have an impact on hand selection, and hand selection can be said to have no impact on environmental or sporting conditions.

As a result, the left hand preference rates of athletes in our study were quite high compared to the general population. In both men and women, there was a negative correlation between both right and left hand 2D:4D and it was also found that the 2D:4D averages of men were lower than that of women. In the right handed and left handed ones, there was a statistically significant difference between the right and left hand 2D:4D ratios in both men and women ( $\mathrm{p}<0.05)$, and the 2D:4D ratios were lower than the 2D:4D ratios. This means that 2D:4D ratios can have an effect on hand selection. 2D:4D ratios can be said to have an effect upon the grip strength and force.

\section{References}

Acar, M. F. (2000). Theory of Training Science Handbook. İzmir.

Atabek, H. C.. (2014). The relationship between hand-grip strength, anaerobic performance and isokinetic muscle strength in female handball players. Niğde University Journal of Physical Education and Sport Sciences, 8, 3,

Bennett, M., Manning, J. T., Cook, C. J., \& Kilduff, L. P. (2010). Digit ratio (2d:4d) and performance in elite rugby 
players. Journal of Sports Sciences, 28, 1415-1421. https://doi.org/10.1080/02640414.2010.510143

Çelik, A., Aksu, F., Tunar, M., Daşdan, A. E. N., \& Topaçoğlu, H. (2010). Master atletlerin fiziksel performans düzeylerinin eldeki parmak oranlarıly ilişkisi, DEÜ Tıp Fakültesi Dergisi, 24, 5-10.

Fink, B., Thanzami, V., Seydel, H., \& Manning, J. T. (2006). Digit ratio and hand-grip strength in German and Mizos men: Cross-cultural evidence for an organizing effect of prenatal testosterone on strength. Am. J. Hum Biol., 18(6), 776-782. https://doi.org/10.1002/ajhb.20549

Foo, L. H. (2007). Influence of body composition, muscle strength, diet and physical activity on total body and forearm bone mass in Chinese adolescent girls. Br. J. Nutr., 98, 1281-1287.

Groslambert, A., Nachon, M., \& Rouillon J. D. (2002). Influence of the age on self-regulation of static grip forces from perceived exertion values. Neurosci. Lett., 325, 52-56. https://doi.org/10.1016/S0304-3940(02)00232-X

Gümüş, M. (2017). Analysis of the relationship between cerebral lateralization and grip strength in elite fencing athletes. IOSR Journal of Sports and Physical Education, 4(5), 1-8.

Hönekopp, J., \& Schuster, M. (2010). A meta-analysis on 2D:4D and athletic prowess: Substantial relationships but neither hand out-predicts the other. Personality and Individual Differences, 48, 4-10. https://doi.org/10.1016/j.paid.2009.08.009

Hönekopp, J., \& Watson, S. (2011). Meta-analysis of the relationship between digit-ratio 2d:4d and aggression. Personality and Individual Differences, 51, 381-386. https://doi.org/10.1016/j.paid.2010.05.003

Hönekopp, J., Manning, J. T., \& Muller, C. (2006). Digit ratio (2D:4D) and physical fitness in males and females: Evidence for effects of prenatal androgens on sexually selected traits. Horm. Behav., 49, 545-549. https://doi.org/10.1016/j.yhbeh.2005.11.006

Jurimae, T., Voracek, M., Jürimäe, J., Lätt, E., Haljaste, K., Saar, M., \& Purge, P. (2008). Relationships between Wnger-length ratios, ghrelin, leptin, IGF axis, and sex steroids in young male and female swimmers. Eur. J. Appl. Physiol., 104, 523-529. https://doi.org/10.1007/s00421-008-0801-z

Kaplan, Ö. D. (2016). Evaluating the relation between dominant and non-dominant hand perimeters and handgrip strength of basketball, volleyball, badminton and handball athletes, International Journal of Environmental and Science Education, 11(10), 3297-3309.

Koley, S., Kaur, S. P., \& Sandhu, J. P. (2011). Correlations of Handgrip Strength and some Anthropometric Variables in Indian Inter-University Female Handball Players. Sport Science Review, 20(3-4), 57-68. https://doi.org/10.2478/v10237-011-0054-3

Kütükçüoğlu, Y. (1993). El Baskınlığının Yönü ve Derecesinin Araştırılması Ankara: GATA Nöroloji AD, expertise thesis. 1993.

Loffing, F., Schorer, J., Hagemann, N., \& Baker, J. (2012). Human handedness in interactive situations: Negative perceptual frequency effects can be reversed! Journal of Sports Sciences, 30, 507-513. https://doi.org/10.1080/02640414.2012.654811

Longman, D., Stock, J. T., \& Wells, J. C. (2011). Digit ratio (2D:4D) and rowing ergometer performance in males and females, Am. J. Phys. Anthropol., 144(3), 337-341. https://doi.org/10.1002/ajpa.21407

Lu, H., Shen, D., Wang, L., Niu, S., Bai, C., Ma, Z., \& Huo, Z. (2017). Digit ratio (2D:4D) and handgrip strength are correlated in women (but not in men) in Hui ethnicity. Early Hum Dev., 109, 21-25. https://doi.org/10.1016/j.earlhumdev.2017.04.005

Lutchmaya, S., Baron-Cohen, S., \& Raggatt, P. (2004). 2nd and 4th digit ratio, fetal testosterone and estradiol. Early Hum. Dev., 77, 23-28. https://doi.org/10.1016/j.earlhumdev.2003.12.002

Malas, M. A., Dogan, S., Evcil, E. H., \& Desdicioglu, K. (2006). Fetal development of the hands, digits and digit ratio (2D:4D). Early Hum. Dev., 82, 469-475. https://doi.org/10.1016/j.earlhumdev.2005.12.002

Manning, J. T., Scutt, D., Wilson, J., \& Lewis-Jones, D. I. (1998). The Ration of 2. To 4. Digit Length: a prediditor of sperm numbers and concentrations of testosterone, luteinizing hormone and oestrogen. Human Report., 13(11), 3000-3004. https://doi.org/10.1093/humrep/13.11.3000

Manning, J. T., \& Taylor, R. P. (2001). Second to fourth digit ratio and male ability in sport: implications for sexual selection in humans. Evolution And Human Behavior, 22, 61-69. https://doi.org/10.1016/S1090-5138(00)00063-5

Manning, J. T. (2002). Digit Ratio: A pointer to fertility. Behavior and health. Rutgers University Press, New Jersey. 3. 
Massey-Westrop, N., Rankin, W., Ahern, M., Krishnan, J., \& Hearn, T. C. (2004). Measuring grip strength in normal adult: reference ranges and a comparison of electronic and hydraulic instruments. J. Hand Surg., 29A, 514-519. https://doi.org/10.1016/j.jhsa.2004.01.012

Moffit, D. M., \& Swanik, C. B. (2010). The association between athleticism, prenatal testosterone and finger length. $J$. Stre. Cond. Res., 20, 55-59.

Muratlı, S. (2007). Antrenman bilimi yaklaşımıyla çocuk ve spor. Ankara. Nobel Yayınları.

Oladipo, G. S., Anugweje, K. C., Ekezie, J., Amasiatu, V. C., Ipigansi, U. N., \& Enefe, G. (2017). Second digit length, fourth digit length and second to fourth digit ratio (2D:4D): Relevance in the choice of female footballer athletes and female non-footballer athletes in Nigeria. Anthropol Open J., 2(1), 23-28. https://doi.org/10.17140/ANTPOJ-2-109

Paul, S. N., Kato, B. S., Hunkin, J. L., Vivekanandan, S., \& Spector, T. D. (2006). The big finger: the second to fourth digit ratio is a predictor of sporting ability in women. British Journal of Sports Medicine, 40, 981-983. https://doi.org/10.1136/bjsm.2006.027193

Pokrywka, L., Rachon, D., \& Suchecka-Rachon, K. (2005). The second to fourth digit ratio in elite and non-elite female athletes. Am. J. Hum. Biol., 17, 796-800. https://doi.org/10.1002/ajhb.20449

Powell, J. L., Parkes, L., Kemp, G. J. (2012). The effect of sex and handedness on white matter anisotropy: a diffusion tensor magnetic resonance imaging study. Neuroscience, 207, 227-242. https://doi.org/10.1016/j.neuroscience.2012.01.016

Tamiya, R., Lee, S. Y., \& Ohtake, F. (2012). Second to fourth digit ratio and the sporting success of sumo wrestlers. Evolution and Human Behavior., 33, 130-136. https://doi.org/10.1016/j.evolhumbehav.2011.07.003

Sudhakar, H. H., Veena, U. B., \& Tejaswi, R. N. (2013). Digit ratio (2D:4D) and performance in Indian swimmers. Indian J. Physiol Pharmacol., 2013 Jan-Mar; 57(1), 72-76.

Tester, N., \& Campell, A. (2007). Sporting achievement: what is the contribution of digit ratio? J. Pers., 75, 663-677. https://doi.org/10.1111/j.1467-6494.2007.00452.x

Troup, J. P. (1999). The physiology and biomechanics of competitive swimming. Clinics in Sport Medicine; 18(2), 267285. https://doi.org/10.1016/S0278-5919(05)70143-5

Van Honka, J., Schutter, D. J., Bos, P. A., Kruijt, A. W., Lentjes, E. G., \& Baron-Cohen, S. (2011). Testosterone administration impairs cognitive empathy in women depending on second-to-fourth digit ratio. Proceedings Of The National Academy Of Sciences Of The United States Of America, 108, 3448-3452. https://doi.org/10.1073/pnas.1011891108

Voracek, M., Reimer, B., \& Ertl, C. (2006). Digit ratio (2D:4D), lateral preferences, and performance in fencing. Percept Mot Skills, 103, 427-446. https://doi.org/10.2466/pms.103.2.427-446

Wind, A. E., Takken, T., Helders, P. J., \& Engelbert, R. H. (2010). Is grip strength a predictor for total muscle strength in healthy children, adolescents, and young adults? Eur. J. Paediatr. 169, 281-287.

https://doi.org/10.1007/s00431-009-1010-4

\section{Copyrights}

Copyright for this article is retained by the author(s), with first publication rights granted to the journal.

This is an open-access article distributed under the terms and conditions of the Creative Commons Attribution license which permits unrestricted use, distribution, and reproduction in any medium, provided the original work is properly cited. 